\title{
Da importância dos recursos hídricos e a organização administrativa para sua proteção
}

The importance of water resources and the administrative organization for their protection

Rocco Antonio Rangel Rosso Nelson ${ }^{1}$

1 Graduado em Direito pela Universidade Potiguar. Mestre em Direito Constitucional pela Universidade Federal do Rio Grande do Norte. Professor do Instituto Federal do Rio Grande do Norte. E-mail: rocconelson@hotmail.com

\begin{abstract}
RESUMO: A pesquisa em tela, fazendo uso de uma metodologia de análise qualitativa, usando-se os métodos de abordagem hipotético-dedutivos de caráter descritivo e analítico, tem por linha de fundo analisar o contexto jurídico da água, no Brasil, em termos gerais, a partir da constatação de sua escassez, do seu acesso desigual, o qual torna-se um empecilho ao desenvolvimento e subsistência da humanidade.
\end{abstract}

Palavras-chave: Meio Ambiente. Proteção. Desenvolvimento. Sustentabilidade. Recursos Hídricos.

\begin{abstract}
Research on screen, making use of a method of qualitative analysis, using the methods of hypothetical-deductive approach of descriptive and analytical character, is the bottom line analysis of the legal context of water, in Brazil, in general terms, the after noting their scarcity, their unequal access, which becomes a hindrance to the development and sustenance of mankind.

Keywords: Environment. Protection. Development. Sustainable Water Resources.
\end{abstract}

SUMÁRIO: Introdução - 1 Do conceito/princípio do desenvolvimento sustentável - 2 A importância da água consumível - Da necessidade urgente de proteção - 3 A natureza jurídica da propriedade da água com o advento da Constituição de 1988; 3.1 Disposições do Código das Águas de 1934; 3.2 A Constituição de 1988; 3.3 Entidades Administrativas de Gerenciamento e Proteção dos Recursos Hídricos - Considerações Finais - Referências

\section{INTRODUÇÃO}

O mundo, hoje, vive um conflito eterno entre os desejos e necessidades dos homens, os quais são ilimitados e insaciáveis, contrapondo-se a conscientização, recente e tardia, de que os recursos naturais são limitados e que em face da degradação podem ser tornar não renováveis.

Milaré (2007), baseado no historiador Wells, afirma que as relações do homem com a Terra tem por paradoxo a corrida entre a educação e o desastre, pois a poluição ambiental não é causada apenas por grandes empresas que lançam seus desejos nos rios sem tratamento, ou toneladas de gases na atmosfera, mas também, a soma da conduta de cada indivíduo 
que utiliza um carro movido a combustível fóssil, ao invés fazer uso de transporte não poluente ou menos poluente, que não tem condutas racionais em economizar energia elétrica ou água, onde o consumismo prevalece e retrata "as pessoas gastam um dinheiro que não possuem, para comprar coisas de que não necessitam, para impressionar pessoas que não conhecem" (MILARÉ, 2007, p. 64).

A necessidade de conscientização das pessoas de que suas condutas repercutem no todo é imperiosa para que a relação entre os homens e o meio ambiente possam se harmonizar. Vislumbre que boa parte dos conflitos locais e mundiais tem ligação direta ou tem por pano de fundo a busca dos recursos naturais tão escassos em decorrência dessa necessidade implacável do homem em sempre querer mais.

Um exemplo é o fato de Israel ter passado muito tempo negando se retirar dos territórios ocupados por causa da água. Mais de $2 / 3$ do abastecimento de água daquele país vêm de lençóis freáticos que ultrapassam seu território (anteriores a 1967), abarcando a Cisjordânia e Golan. Outros exemplos são os vários massacres na África, sob o pretexto de questões raciais, no Zaire, Ruanda ou Uganda, são conflitos em busca de recursos naturais, sobretudo de água. (MILARÉ, 2007).

De forma mais contemporânea, tem-se a intervenção americana no Iraque com o mote de acabar com o regime ditatorial de Saddam Hussein e proporcionar a implantação de um Estado Democrático, mas tendo por interesse a questão do petróleo, recurso natural que teve o barril vendido a mais de $\mathrm{R} \$ 120$ dólares em 2008.

Assim, afirmar-se que o desenvolvimento não se restringe a ideia de desenvolvimento econômico. As cifras da economia só têm sentido quando compatibilizados com um proporcional desenvolvimento social e preservação do meio ambiente. Essa tríade visão do que compõe o desenvolvimento tem por base a concepção do desenvolvimento sustentável, sendo esta a única alternativa, para a situação crítica em que se encontra o planeta.

\section{DO CONCEITO/PRINCÍPIO DO DESENVOLVIMENTO SUSTENTÁVEL}

A necessidade de proteção ao meio ambiente é patente e imanente. Entretanto, ainda desenvolve-se um processo de conscientização, o qual teve início a mais de 30 anos, quando da constatação de que apesar de uma época de ouro para o desenvolvimento econômico e social (período do Welfare State), a permanência dessa situação não subsistiria em face da degradação ambiental em escala mundial.

Essa ação de conscientização, em caráter internacional, deu-se em 1972 com a Conferência das Nações Unidas sobre o Meio Ambiente Humano (CNUMAH), em Estocolmo, tendo a participação de 113 países, onde pela primeira vez se confrontou o desenvolvimento econômico com a necessidade de preservação do meio ambiente (DNUMAH, 1972).

Tanto que um dos grandes impasses foi que os países desenvolvidos, que já estavam com seu ambiente extremamente comprometido queria impor meios de controle ambiental aos Estados em processo de desenvolvimento, na busca pela preservação de suas riquezas naturais. Tal situação gerou grande mal estar, pois isso tornaria os ricos, ainda ricos e os po- 
bres, mais pobres.

Assim, o slogan da campanha dos países terceiro-mundistas era que a maior poluição é a pobreza e que a industrialização suja é melhor que a pobreza limpa. Dessa conferência tem como fruto a criação do Programa das Nações Unidas para o Meio Ambiente (PNUMA), bem como uma declaração sobre o meio ambiente humano, composto de 26 princípios os quais vieram por nortear o processo decisório em matéria ambiental (DNUMAH, 1972).

Nessa toada de conscientização internacional, em 1983, com a Conferência das Nações Unidas sobre o Meio Ambiente e Desenvolvimento, foi instituída a Comissão Mundial sobre Meio Ambiente e Desenvolvimento, sob a coordenação de Gro Harlem Brundtland, primeira ministra da Noruega, que tinha por objetivo examinar questões críticas sobre o meio ambiente, desenvolver fórmulas de cooperação internacional e elevar o nível de compreensão e conscientização sobre a importância do meio ambiente.

Em 1987, a comissão apresentou o resultado do trabalho intitulado Nosso Futuro Comum, o qual ficou conhecido como relatório Brundtland. Documento que é o grande marco do processo de mobilização do mundo em favor do meio ambiente. Na década de 1990 ocorreu a Conferência das Nações Unidade sobre Meio Ambiente e Desenvolvimento Sustentável (CNUMAD), chamado de Cúpula da Terra, que aconteceu no Rio de Janeiro, ficando conhecido como Eco/92 ou Rio/92, teve a participação de 172 países e de aproximadamente 10.000 participantes, o qual teve por mérito a cunhagem da expressão desenvolvimento sustentável, com a publicação da Declaração do Rio sobre o meio ambiente e desenvolvimento, com 27 princípios, e da Agenda 21.

É imperioso conceber a real dimensão do desenvolvimento sustentável, não como uma bandeira proposta por ecologistas e ambientalistas radicais ou moderados, sendo esta a visão dos leigos em face das informações distorcidas ou equivocadas da mídia, mas sim, como um fim que tem por base o tripé da interação harmônica e pacífica entre a sociedade, a economia e meio ambiente. Nesse sentido o princípio $8^{\circ}$ da Declaração de Estocolmo enuncia que "O desenvolvimento econômico e social é indispensável para assegurar ao homem um ambiente de vida e trabalho favorável e para criar na terra as condições necessárias de melhoria da qualidade de vida" (DNUMAH, 1972, Princípio 8o).

Esse, também, é o cerne da Declaração do Rio sobre Meio Ambiente e Desenvolvimento (1992) "Para alcançar o desenvolvimento sustentável, a proteção ambiental constituirá parte integrante do processo de desenvolvimento e não pode ser considerada isoladamente deste". (Princípio $4^{\circ}$ ). Assim, a questão da proteção ambiental por meio de um planejamento racional não pode ser vista como um obstáculo ao desenvolvimento seja econômico ou social, mas sim, como elemento necessário para promoção de tal desenvolvimento, assim como garantia da perpetuidade desse desenvolvimento para gerações futuras. A esse respeito Milaré (2007, p. 62) afirma que

Compatibilizar meio ambiente com desenvolvimento significa considerar os problemas ambientais dentro de um processo contínuo de planejamento, atendendo-se adequadamente às exigências de ambos e observando-se as suas inter-relações particulares a cada contexto sociocultural, político, econômico e ecológico, dentro de 
uma dimensão tempo/espaço. Em outras palavras, isto implica dizer que a política ambiental não deve erigir-se em obstáculo ao desenvolvimento, mas sim em um de seus instrumentos, ao propiciar a gestão racional dos recursos naturais, os quais constituem a sua base material.

Chama a atenção, a certa discussão que há sobre o desenvolvimento sustentável de que se este seria ou não um princípio constitucional, albergado na Constituição da República Federativa do Brasil (CRFB) de 1988. Milaré (2007) defende ser o princípio do desenvolvimento sustentável uma questão de lógica, um processo, um conceito, onde o seu desrespeito ocasionará o perecimento de tudo e de todos. Para este autor (p. 70).

Não figura, por ora, no Direito do Ambiente, a consagração do 'desenvolvimento sustentável' nem da 'sustentabilidade' como normas explícitas e bem definidas de conduta da sociedade ou do Poder Público, uma vez que nenhum instrumento legal propôs-se a defini-las, consignar formalmente as suas características e estabelecer formas e requisitos para sua aplicação.

Autores como Sirvinskas (2003) e o próprio Supremo Tribunal Federal (STF) vislumbram que o princípio do desenvolvimento sustentável seria um princípio constitucional, da qual se extrai do art. 225, caput, da CRFB. Neste sentido é o voto do ministro Celso de Mello (STF), em medida cautelar em uma ação direita de inconstitucionalidade, onde afirmou que

A atividade econômica não pode ser exercida em desarmonia com os princípios destinados a tornar efetiva a proteção ao meio ambiente. - a incolumidade do meio ambiente não pode ser comprometida por interesses empresariais nem ficar dependente de motivações de índole meramente econômica, [...] A questão do desenvolvimento nacional (CF, art. 3으. II) e a necessidade de preservação da integridade do Meio ambiente (CF, art. 225): O princípio do desenvolvimento sustentável como fator de obtenção do justo equilíbrio entre as exigências da economia e as da ecologia. $\mathrm{O}$ princípio do desenvolvimento sustentável, além de impregnado de caráter eminentemente constitucional, encontra suporte legitimador em compromissos internacionais assumidos pelo Estado brasileiro e representa fator de obtenção do justo equilíbrio entre as exigências da economia e as da ecologia, subordinada, no entanto, a invocação desse postulado, quando ocorrente situação de conflito entre valores constitucionais relevantes, a uma condição inafastável, cuja observância não comprometa nem esvazie o conteúdo essencial de um dos mais significativos direitos fundamentais: o direito à preservação do meio ambiente, que traduz bem de uso comum da generalidade das pessoas, a ser resguardado em favor das presentes e futuras gerações (STF, PLENO, ADI-MC 3540/DF, rel. Min. Celso de Mello, DJU 03.02.2006, p. 14).

Assevera que tal discussão é na verdade infrutífera, pois independentemente do princípio do desenvolvimento sustentável ter caráter constitucional ou não, ele deve ser respeitado pelo articulador do direito e erigido a standard para desenvolvimento da sociedade, da economia e do meio ambiente, sem o qual esse desenvolvimento, a vida e a qualidade de vida das pessoas serão sumariamente alijados. 


\section{A IMPORTÂNCIA DA ÁGUA CONSUMÍVEL - NECESSIDADE URGENTE DE PROTEÇÃO}

Um dos recursos do meio ambiente (BRASIL, Lei $n^{\circ}$ 6.938/1981- PNMA, art. $3^{\circ}$ ) que necessita de gerenciamento sustentável e que gradativamente tem a sua importância reconhecida é a água ou recursos hídricos (que embora conceitualmente diferentes, neste texto será considerados sinônimos) sendo um elemento vital para o desenvolvimento e sobrevivência dos seres vivos na Terra (CUSTÓDIO, 2005). A esse respeito Silva (2007, p. 120) expõe a importância da água afirmando que

A água é um bem indispensável à vida: humana, animal e vegetal. Compartilha dos processos ecológicos essenciais, como o da fotossíntese, o da quimiossíntese e o da respiração. Funciona como habitat e nicho ecológico de inúmeros organismos e espécies animais e vegetais. Sua mobilidade, seu poder de solubilidades, sua variação de densidade, sua característica de regulador térmico e especialmente sua tensão superficial são atributos que respondem por sua extraordinária função ecológica.

A portaria no 518, de 25 de março de 2004 (Revogada), do Ministério da Saúde, no seu art. $4^{\circ}$, I, Conceituou legalmente água: "água para consumo humano cujos parâmetros microbiológicos, físicos, químicos e radioativos atendam ao padrão de potabilidade e que não ofereça riscos à saúde". Para Leuzinger (2005) esse elemento vital está passando, na realidade atual, por sérios problemas em relação a sua quantidade e qualidade, visto que se constata que mais de um bilhão, mais ou menos um quinto da população mundial não tem acesso adequado a esse recurso natural. A perspectiva é de que tal situação tende a se agravar (XAVI$E R, 2004)$.

O problema da falta e da qualidade da água é algo tão sério que Setti et al (2001, p. 46) dimensionam a questão da seguinte forma "segundo estudo de especialista a previsão de que sem um gerenciamento sustentável desse recurso natural, em 30 anos a escassez de água reflita em cinco bilhões e meio de pessoas". Presentemente, a água passa a ser uns dos principais recursos naturais, inclusive sendo fonte de conflito armado em âmbito internacional. Para Antunes (2007, p. 688) "a ONU reconhece a existência de, pelo menos 156 grandes disputas internacionais envolvendo a utilização de recursos hídricos. Os conflitos internos chegam a milhares".

De forma mais clarividente, percebe que a última agressão dos Estados Unidos ao Iraque, não foi decorrente, tão somente, por uma questão de petróleo, mas também, pela capacidade hídrica desse país, isso constatado no primeiro Fórum Alternativo Mundial, realizado em Florença, Itália. O Iraque é o país do Oriente médio mais rico em água, sendo banhados pelos rios Tigre e Eufrates. Ou seja, o controle do Iraque significa o controle da água nessa região. Viegas (2005, p. 35-36) afirma que

Contudo, tem-se dito que o Século XXI será marcado não mais por disputas em torno do petróleo, mas em razão da água. Os conflitos já constituem uma realidade, e desenvolver-se-ão em todos os níveis, atingindo desde as pequenas comunidades até a 
relação entre países ou blocos de países. É indiscutível que sempre há interesses econômicos por trás das guerras, e com a água não será diverso, pois aqueles que detiverem o seu controle se tornarão poderosos - ou ainda mais que já o sejam - em nível global. Diversa, entretanto, poderá ser a forma de se pôr fim a essas lutas, na medida em que, ao contrário do que ocorre com o petróleo, a água jamais será substituída por outro bem, seja ele natural ou artificial, dadas suas qualidades e seus múltiplos usos.

Assevera-se a situação de crise de sustentabilidade em que passa o mundo, em vista da pouquíssima disponibilidade de água doce no nosso planeta. Afere-se que $97,5 \%$ dessa água é salgada, sendo apenas $2,5 \%$ doce. Desses $2,5 \%$ de água doce, $68,7 \%$ estão localizados em áreas polares, $30,1 \%$ estão em reservatório subterrâneos, sendo apenas $0,27 \%$ do volume de água doce encontrado em rios e lagos, o que equivale 0, 007\% do volume total da Terra.

Se já não bastasse, apenas $2,5 \%$ da água do mundo ser de natureza doce, averigua que no meio natural eleva a dificuldade do seu acesso, em virtude de que dois terços $(68,7 \%)$ se encontram nas calotas polares, a outra parte, quase um terço $(30,1 \%)$ encontra-se em aquíferos subterrâneos, restando apenas $0,27 \%$ de água disposta em lagos e rios, conforme demonstra figura 01.

Machado (2002) e Freitas (2008) destacam que o aquífero Guarani, é o maior manancial transfronteiriço do mundo, onde $2 / 3$ do seu volume encontra-se em território brasileiro (abrangendo os Estados de Goiás, Mato

Grosso do Sul, Minas Gerais, São Paulo, Paraná, Santa Catarina e Rio grande do Sul), vindo a abastecer, também, o Paraguai, Argentina e Uruguai.

Figura 01 - Localização da água doce disponível

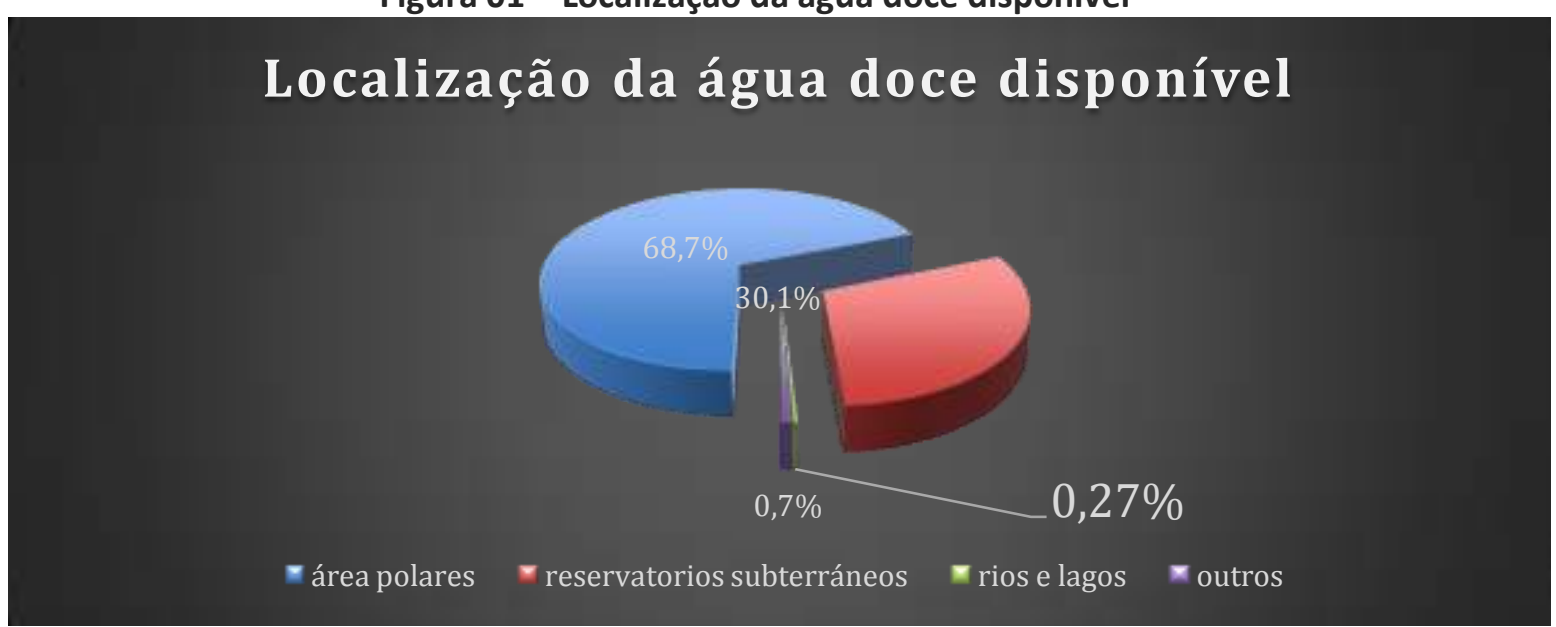

Fonte: Adaptado Carvalho (2004).

Percebe-se que os recurso hídrico de acesso fácil, apresenta apenas 0,27\% para ser administrado para o consumo humano, uso industrial, consumo de animais, uso agrícola, sem considerar as reservas de água que se encontram já poluídas pelo lançamento não tratado de dejetos industriais e esgotos, as quais não possuem viabilidade atual de uso, além de que esse uso vem aumentando ano após ano. 
O problema da poluição de água é algo tão sério e tão precário nos países em desenvolvimento que a água de má qualidade ou contaminada é responsável por mais de $80 \%$ das doenças (como a cólera, doença de extrema disseminação pela água) e de 1/3 da taxa de mortalidade (ANTUNES, 2007). Já o relatório da ONU afirma que $90 \%$ das águas utilizadas em países em desenvolvimento são devolvidas ao meio ambiente sem o devido tratamento (GRAF, 2008).

Não só a falta de água compromete a existência da vida das pessoas e seres vivos, mas, de forma mais devastadora isso se sucede com a água poluída ou contaminada, tanto em relação aos seres humanos, como para animais ou plantas (Freitas, 2008). O índice da qualidade da água tornou-se algo tão importante que por meio dele é capaz de diagnosticar a conservação do meio ambiente, possibilitando determinar grau de erosão do solo, lançamentos orgânicos, poluição por esgoto, poluição atmosférico e outras, o que vem justificar não só o uso das bacias hidrográficas como unidade de planejamento, como a proximidade da gestão hídrica com a gestão ambiental.

Já em relação ao uso indiscriminado da água, segundo o estudo "Cuidando do Planeta Terra - Uma Estratégia para o Futuro da Vida" vislumbra como se encontra comprometido à existência da vida no planeta em decorrência do manejo irracional dos recursos hídricos, a esse respeito Antunes (2007, p. 687) afirma que

O nosso uso de água está criando uma crise em grande parte do mundo. Estima-se que as retiradas totais de água tenham aumentado mais de 35 vezes durante três séculos, e que devem aumentar 30-35\% até o ano de 2000. Os níveis atuais de uso de água doce não poderão ser mantidos se a população humana atingir 10 bilhões em 2050.

Outro autor que discute o uso da água é Carvalho (2004, p. 03) afirmando que

Um fator preocupante consiste na crescente dinâmica de consumo de água pelo mundo. Estima-se um consumo mundial entre 2.879 a $5.187 \mathrm{~km}^{3} /$ ano, para o ano de 2.025, o que representa um crescimento de aproximadamente, $75 \%$ (setenta e cinco por cento), em 30 anos, do volume de água utilizado em todo o planeta.

Não só constata-se um aumento gradual do uso da água como esse uso é realizado de forma desigual no mundo. Um cidadão europeu tem um gasto de água 70 vezes maior que um habitante de Gana, enquanto que o norte-americano tem gasto de 300 vezes em relação ao ganense. Ou seja, os próprios dados sobre o uso de água reflete a distinção entre norte e sul no mundo, bem como é um dos indicadores da distinção ente classes sociais (ANTUNES, 2007). Corrobora com essa ideia Caubet (2006, p. 19-20) apresenta uma situação que retrata bem o acesso desigual da água doce na África e no Oriente Médio.

Os 600.000 fazendeiros brancos da África do Sul que praticam a irrigação consomem $60 \%$ dos recursos hídricos do país, face a 15 milhões de negros que não têm acesso à água potável. Os palestinos, a duras penas, chegam a conseguir autorização para fu- 
rar poços até 140 metros de profundidade, enquanto os poços das áreas ocupadas por colonos israelenses podem alcançar 800 metros ... As mulheres e moças da África rural passam cerca de três horas por dia caminhando para buscar água. Essa atividade consome um terço das calorias que elas absorvem na sua alimentação.

Averbe-se que $70 \%$ da água captada destina-se a agricultura, sendo $20 \%$ no uso industrial e o restante, $10 \%$ no abastecimento humano (figura 02). Esses dados corroboram a frase "água é vida, água é comida", pois esse elemento não só é necessário para o consumo humano, como é o elemento chave para toda a nossa produção agrícola, bem como pecuarista (SETTI ET AL, 2001, p. 54). Chama-se a atenção ao grande desperdício de água realizado na agricultura, visto que quase $60 \%$ do seu volume total são perdidos antes de atingir a planta (ANTUNES, 2007).

Figura 02 - Distribuição do volume captada por setor

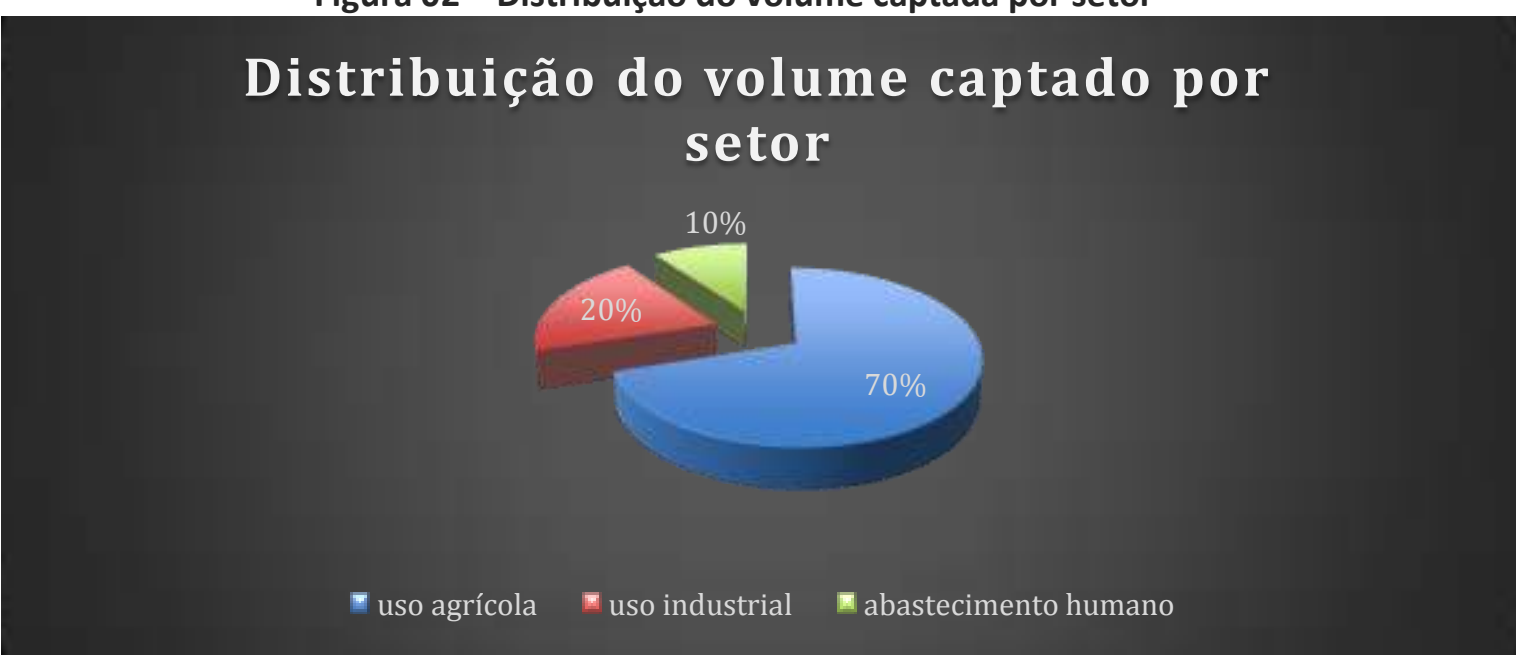

Fonte: Setti et al (2001).

Custódio (2005, p. 523-524) discute sobre às grandes necessidades de água nas indústrias, afirmando que

[...] são enormes as necessidades das indústrias: a siderurgia consome $150 \mathrm{~m}^{3}$ por tonelada de aço produzido; as indústrias e pastas de papel e de fabricação de papel, as indústrias químicas em geral bem como as indústrias alimentícias são as maiores consumidoras de água. A presença da água tanto no início como no final do ciclo industrial constitui importante fator quando se trata de localização - usinas e dos centros industriais, em face das iminentes consequências poluentes com o lançamento de seus resíduos sólidos, líquidos ou gasosos nas águas, notadamente dos rios e do mar.

Descortina-se, assim, um verdadeiro estado de emergência para a manutenção da sobrevivência humana, e vem aumentando cada vez mais a importância de tecnologias que permitam a diminuição do consumo de água, processos de tratamento e de despoluição da mesma, na exploração de aquíferos, sendo imperiosa a participação do direito para regular a 
exploração da água, visando proporcionar um gerenciamento sustentável desse recurso natural tão necessário, para que todos tenham acesso em quantidade suficiente as suas necessidades e de boa qualidade, efetivando, assim, o direito à vida e o princípio supremo da dignidade da pessoa humana e o plexo de direitos decorrentes do mesmo (FREITAS, 2008).

Essa visão de gerenciamento sustentável é imperiosa para garantir o futuro da humanidade, bem como das próximas gerações, pois apesar do Brasil deter 13,4\% da água doce do mundo (equivalente a $53 \%$ do total do continente sul-americano) (LEUZINGER, 2005). problemas em decorrência da água são inúmeros e constantes, como bem explicita Freitas (2008, p 18-19).

\begin{abstract}
O Brasil, nos últimos anos, vem tomando consciência do problema. Afinal, um povo que possui os maiores rios do mundo tem dificuldade em imaginar que pode ficar sem água. Mas, apesar de termos cerca de $13,7 \%$ da água doce disponível no mundo a verdade é que os problemas vêm se agravando. No Nordeste a falta de água crônica. No Sudeste ela é abundante, porém de má qualidade. A invasão de áreas de mananciais hídricos pela população carente é um dos maiores problemas São Paulo. Os dejetos industriais lançados no rio Paraíba do Sul tornam precária a água que abastece o Rio de Janeiro e outras cidades. Falta água para irrigar arrozais do Rio Grande do Sul.
\end{abstract}

O planeta oferta 113 trilhões de metros cúbicos de água para o surgimento e manutenção da vida na terra e do homem, sendo que 17 milhões de metros cúbicos dessa água estão vinculadas ao território brasileiro. Embora seja possível afirmar que o Brasil é o país com maior volume de água doce, segundo os dados trazido à baila, o mesmo não fica bem colocado segundo um índice mundial de pobreza da água (Water Poverty Index - WPI), o qual é constituído tendo por bases a análise de diferentes medidas como recursos, acesso, capacidade, uso e impacto ambiental.

Os índices mostram que os países mais ricos em água são: Finlândia Canadá, Islândia, Noruega, Guiana, Suriname, Áustria, Irlanda, Suécia e Suíça. Em contrapartida as mais pobres são Haiti, Níger, Etiópia, Eritréia, Malawi, Dijibouti, Tchad, Benin, Ruanda e Borundi. O Brasil com uma pontuação de 61,2 ficou na $50^{\circ}$ colocação, no bloco intermediário alto. Entretanto, no requisito acesso de água ficou lotado entre os 10 piores do mundo (WPI, Acesso 2013).

Fica evidenciado, por essas informações, como a água em relação a sua disponibilidade, acesso e nível de qualidade possibilita avaliar o desenvolvimento de uma nação, nos seus aspectos de educação, saúde, discrepância ou não entre classes sociais e renda. Não é por menos que os primeiros colocados no WPI são países que conseguem ofertar uma alta qualidade de vida aos seus cidadãos com altas taxas de desenvolvimento humano, índices não alcançados pelo Brasil

A acuidade do problema sobre a escassez de água doce e a necessidade de proteção dos recursos hídricos chegou a um patamar tal, repercutindo nos debates internacionais, que se tornou uns dos temas principais da convocação da CNUMAD (Rio/92), tendo sido destinado na Agenda 21, uns dos principais documentos elaborados nessa conferência, dois capítulos diretamente relacionados a água (capítulo 17 - proteção dos oceanos e capítulo 18 - pro- 
teção da qualidade e suprimento de água potável).

Em janeiro de 1992, no mesmo ano da Rio/92, a grave situação da disponibilidade da água já havia levado a comunidade internacional a se organizar, realizando a Conferência Internacional sobre Água e Desenvolvimento, em Dublim, Irlanda e eleger os princípios fundamentais sobre a utilização da água e sua conservação para as gerações futuras, como elenca Antunes (2007, p. 689):
a) a água é um recurso finito e vulnerável, essencial para a manutenção da vida, do desenvolvimento e do meio ambiente;
b) o desenvolvimento e a administração da água devem estar baseados em uma a- bordagem participativa, envolvendo os usuários, planejadores e elaboradores de po- líticas públicas, em todos os níveis;
c) a mulher desempenha um papel central na administração, na proteção e na provi- são da água;
d) a água tem valor econômico em todos os seus usos e deve ser reconhecida como um bem econômico.

Nesse contexto, surge de forma imperiosa, no Brasil, a necessidade e a importância da Lei no 9.433/97, que instituiu a Política Nacional de Recursos Hídricos (PNRH) e cria o Sistema Nacional de Gerenciamento de Recursos Hídricos (SINGREH), tendo em vista que o país, detém $13,7 \%$ da água no mundo, vindo a encabeçar a lista dos nove países que dividem $60 \%$ da água doce no mundo.

É cediço que muito mais que uma problemática que necessita de regulação pelo direito, ver-se uma questão cultural no Brasil, pois um país onde a água é vista como bem infinito e disponível gratuitamente gera uma cultura/mentalidade de desperdício (banhos longos, lavagem de calçadas diárias, descasos com vazamentos, dentre outros desperdícios). Essas práticas realizadas em conjunto pela população se tornam um verdadeiro crime praticado necessariamente por várias pessoas contra o meio ambiente. Para Freitas (2008) a exempli gratia, uma simples torneira cotejando pode gerar o desperdício de 46 litros de água ao dia.

Apesar dessa situação ímpar que o Brasil se encontra, em face da sua dimensão geográfica, ele não possui uma distribuição uniforme dos recursos hídricos, onde $73 \%$ da água se concentra na Bacia Hidrográfica Amazônica, sendo esta habitada por menos de 5\% da população (BRUNONI, 2008). Enquanto que a Bacia Hidrográfica do Paraná, que abrange os Estados de Minas Gerais, Goiás, Mato Grosso do Sul, São Paulo, Paraná, Santa Catarina e o Distrito Federal, concentra-se $31,8 \%$ da população, tendo a sua disponibilidade hídrica resumido a apenas $6 \%$ (CARVALHO, 2004).

Observa-se que a disponibilidade água per capita no país é desigual. Mesmo detendo uma quantidade vastíssima desse recurso natural o seu acesso em quantidade e qualidade não é uniforme para toda a população, gerando crises setoriais, o que vem por reforçar a necessidade e a importância da busca de um gerenciamento sustentável da água. A Bacia Amazônica tem disponibilidade de $628.940 \mathrm{~m}^{3}$ por pessoa ao ano, enquanto na Bacia do Atlântico Leste, tem disponibilidade de $3.820 \mathrm{~m}^{3}$ por pessoa ao ano, havendo, enorme discrepância (CARVALHO, 2004).

Planeta Amazônia: Revista Internacional de Direito Ambiental e Políticas Públicas 
Para Borsoi e Torres (1997, p. 5) a divisão regional de disposição hídrica no Brasil ocorre da seguinte maneira:

[...] é de $70 \%$ para a região Norte, $15 \%$ para a Centro-Oeste, $12 \%$ para as regiões Sul e Sudeste, que apresentam o maior consumo de água, e 3\% para a Nordeste (...situação agravada por um regime pluviométrico irregular e pela baixa permeabilidade do terreno cristalino).

Corrobora com as afirmações alhures, sobre a contradição existente no Brasil, de que mesmo sendo o país com maior disponibilidade hídrica no mundo (35 mil $\mathrm{m}^{3}$ de água per capita por ano, sendo quase 17 vezes o da Alemanha e quase 10 vezes da França), apresenta locais e populações que padecem da sua disponibilidade reduzida (GRAF, 2008). Carvalho (2004, p. 6) explica que os principais motivos da escassez de água no país

[...] decorrem principalmente da combinação do crescimento exagerado das demandas localizadas e da degradação da qualidade das águas. Esse quadro decorre do modelo de crescimento industrial concentrado, do aumento e da concentração populacional, da exclusão social, do processo de industrialização e expansão agrícola, verificados a partir da década de 1950.

Em razão da importância da água doce para a existência e desenvolvimento humano, bem como pela constatação da realidade de sua escassez, qualidade comprometida, distribuição não isonômica e uso irracional acredita-se que a Lei no 9.433/97-PNRH e a criação do SINGREH traz as diretrizes para a tomada de consciência de que a água é um bem finito, vulnerável e dotado de caráter econômico, e necessita de proteção e informa os preceitos mínimos para a busca de um gerenciamento sustentável e a promoção da dignidade da pessoa humana, fundamentado na CRFB.

\section{A NATUREZA JURÍDICA DA PROPRIEDADE DA ÁGUA COM O ADVENTO DA CONSTITUIÇÃO DE 1988}

\subsection{DISPOSIÇÕES DO CÓDIGO DAS ÁGUAS DE 1934}

A primeira parte do Código de Águas aprovado pelo Decreto no 24.643, de 1934 tratava das águas em geral e o seu domínio, já a segunda parte abordava a água no aproveitamento industrial, principalmente no que tange a energia hidráulica e sua produção. O Código dividia a águas em três classes: águas públicas de uso comum, águas comuns e águas particulares.

As águas públicas de uso comum eram: os mares territoriais, nos mesmos incluídos os golfos, baias, enseadas e portos; b) as correntes, canais, lagos e lagoas navegáveis ou flutuáveis; c) as correntes de que se façam estas águas; d) as fontes e reservatórios públicos; e) as nascentes quando forem de tal modo consideráveis que, por si só, constituam o caput fluminis; f) os braços de quaisquer correntes públicas, desde que os mesmos influam na navegabi- 
lidade ou flutuabilidade (BRASIL, DECRETO nํ 24.643/1934, art. 2ㅇ).

De acordo com o art. 29 deste Decreto as águas públicas de uso comum podiam ser da União, Estados e dos Municípios. As águas da União eram as marítimas, situadas nos territórios federais, as que servem de limitem da República com as nações vizinhas, quando sirvam de limites entre dois ou mais Estados ou percorram mais e um Estado. As águas do domínio estadual eram aquelas que serviam de limite entre dois ou mais municípios ou percorressem mais de um município. Seriam, por fim, municipais, quando situados exclusivamente em território municipal

O artigo 70 do Decreto no 24.643/1934 determinava que as águas comuns eram as correntes não navegáveis ou flutuáveis. Essa espécie de águas não possui domínio, sendo considerados bens de todos (MILARÉ, 2007). Já as águas particulares, segundo o artigo 80 diziam respeito às nascentes e todas as águas situadas em terrenos particulares, quando as mesmas não estiverem classificadas entre as águas comuns de todos, as águas públicas ou as águas comuns.

\subsection{A CONSTITUIÇÃO DE 1988}

A necessidade de regulação da água sobreveio com a imperiosidade da produção de energia elétrica para a indústria, no século XX. Em decorrência da constatação da escassez desse recurso natural, o aumento em proporções geométricas com o passar dos anos, além, do problema com a poluição e com vistas a concretizar o ideário do desenvolvimento sustentável. A CRFB de 1988 converteu todas as águas em domínio público, inclusive as subterrâneas, não existindo mais águas de propriedade particular.

$\mathrm{O}$ artigo 20 da CRFB determina como bens da União: a) os lagos, rios e quaisquer correntes de água em terrenos de seu domínio, ou que banhem mais de um Estado, sirvam de limites com outros países, ou se estendam a território estrangeiro ou dele provenham, bem como os terrenos marginais e as praias fluviais; b) as ilhas fluviais e lacustres nas zonas limítrofes com outros países; as praias marítimas; as ilhas oceânicas e as costeiras, excluídas, destas, as que contenham a sede de Municípios, exceto aquelas áreas afetadas ao serviço público e a unidade ambiental federal, e as referidas no art. 26, II; c) o mar territorial; d) os potenciais de energia hidráulica e; e) os recursos minerais, inclusive os do subsolo (BRASIL, CRFB, 1988, art. 20).

Tal realidade constituída pela Constituição de 1988 é reflexo da água como direito fundamental a vida, liberdade e saúde, o qual não pode ficar ao alvitre dos interesse particulares. A periculosidade de ter as águas nas mãos dos particulares é tamanha, que a PNRH tem como fundamento, no seu artigo 10, a dominialidade pública da água. No ordenamento atual, os particulares são meros detentores dos direitos de uso de recursos hídricos, desde que detenham a outorga para tanto (BRASIL, Lei no 9.433/1997, art. 12). Constata-se, ainda, que não há mais águas no domínio dos Municípios (SILVEIRA NETO, 2008), sendo esses bens públicos da União ou dos Estados (BRASIL, CRFB, 1988, art. 26). 


\subsection{ENTIDADES ADMINISTRATIVAS DE GERENCIAMENTO E PROTEÇÃO DOS RECURSOS HÍDRI-} $\cos$

Em decorrência do movimento de criação de políticas nacionais relacionado ao meio ambiente, como: Biodiversidade, Urbana, Educação Ambiental, Saneamento Básico e Desenvolvimento Sustentável dos Povos e Comunidades Tradicionais, criou-se a PNRH, (Lei $\mathrm{n}^{\circ}$ 9.433/97), o qual para ganhar delineamento necessita de estruturas de órgãos e entidades administrativas, constituindo verdadeiras engrenagens para promoção dos objetivos e fins dessa política ambiental.

A PNRH, constituiu o SINGREH que se assemelha a estrutura do Sistema Nacional do Meio Ambiente (SISNAMA), Lei $n^{\circ} 6.938 / 81$. O SINGREH é um sistema nacional, pois abarca não apenas o âmbito federal, mas também o estadual e municipal, sendo composto por várias entidades dos três níveis da federação. Essa arquitetura político-administrativa é composta pelo: Conselho Nacional de Recursos Hídricos, Agência Nacional de Águas, Conselhos de Recursos Hídricos dos Estados e do Distrito Federal, os Comitês de Bacia Hidrográfica, órgãos dos poderes públicos federal, estaduais, do Distrito Federal e municipais cujas competências se relacionem com a gestão de recursos hídricos e, por fim, as Agências de Água (BRASIL, Lei no 9.433/97, art. 33).

Os principais objetivos do SINGREH são: $a$ ) Coordenar a gestão integrada das águas; $b$ ) Arbitrar administrativamente os conflitos relacionados com os recursos hídricos; $c$ ) Implementar a PNRH, d) planejar, regular e controlar o uso, a preservação e a recuperação dos recursos hídricos e e) Promover a cobrança pelo uso de recursos hídricos (BRASIL, Lei no 9.433/97, art. 32). E tem como competência de acordo com a Lei no 9.433/97, art. 35).

I - promover a articulação do planejamento de recursos hídricos com os planejamentos nacional, regional, estaduais e dos setores usuários; II - arbitrar, em última instância administrativa, os conflitos existentes entre Conselhos Estaduais de Recursos Hídricos; III - deliberar sobre os projetos de aproveitamento de recursos hídricos cujas repercussões extrapolem o âmbito dos Estados em que serão implantados; IV - deliberar sobre as questões que the tenham sido encaminhadas pelos Conselhos Estaduais de Recursos Hídricos ou pelos Comitês de Bacia Hidrográfica; V - analisar propostas de alteração da legislação pertinente a recursos hídricos e à Política Nacional de Recursos Hídricos; VI - estabelecer diretrizes complementares para implementação da Política Nacional de Recursos Hídricos, aplicação de seus instrumentos e atuação do Sistema Nacional de Gerenciamento de Recursos Hídricos; VII - aprovar propostas de instituição dos Comitês de Bacia Hidrográfica e estabelecer critérios gerais para a elaboração de seus regimentos; IX - acompanhar a execução e aprovar o Plano Nacional de Recursos Hídricos e determinar as providências necessárias ao cumprimento de suas metas; $\mathrm{X}$ - estabelecer critérios gerais para a outorga de direitos de uso de recursos hídricos e para a cobrança por seu uso; XI - zelar pela implementação da Política Nacional de Segurança de Barragens (PNSB); XII - estabelecer diretrizes para implementação da PNSB, aplicação de seus instrumentos e atuação do Sistema Nacional de Informações sobre Segurança de Barragens (SNISB); XIII - apreciar o Relatório de Segurança de Barragens, fazendo, se necessário, recomendações para melhoria da segurança das obras, bem como encaminhá-lo ao Congresso Nacional. 
O Conselho Nacional de Recursos Hídricos (CNRH) é auxiliado por uma secretaria executiva integrante do MMA, a qual tem a função de prestar apoio administrativo, técnico e financeiro ao Conselho e instituir os expedientes provenientes dos CNRH e dos Comitês de Bacia Hidrográfica, além de elaborar seu programa de trabalho e respectiva proposta orçamentária anual e submetê-los à aprovação do CNRH (BRASIL, Lei no 9.433/97, art. 46). Existe um conselho semelhante ao nacional, só que em âmbito estadual, bem como no Distrito Federal, como corolário do sistema federativo adotado no Brasil.

A Agência Nacional de Água (ANA) passou a compor o SINGREH com a aprovação da Lei $n^{\circ}$ 9.984/00, é uma entidade administrativa de natureza autárquica e tem como atribuições, de acordo com seu art. $4^{\circ}$ :

I - supervisionar, controlar e avaliar as ações e atividades decorrentes do cumprimento da legislação federal pertinente aos recursos hídricos; II - disciplinar, em caráter normativo, a implementação, a operacionalização, o controle e a avaliação dos instrumentos da Política Nacional de Recursos Hídricos; IV - outorgar, por intermédio de autorização, o direito de uso de recursos hídricos em corpos de água de domínio da União, observado o disposto nos arts. $5^{\circ}, 6^{\circ}, 7^{\circ}$ e $8^{\circ} ; \mathrm{V}$ - fiscalizar os usos de recursos hídricos nos corpos de água de domínio da União; VI - elaborar estudos técnicos para subsidiar a definição, pelo Conselho Nacional de Recursos Hídricos, dos valores a serem cobrados pelo uso de recursos hídricos de domínio da União, com base nos mecanismos e quantitativos sugeridos pelos Comitês de Bacia Hidrográfica, na forma do inciso VI do art. 38 da Lei $n^{\circ}$ 9.433, de 1997; VII - estimular e apoiar as iniciativas voltadas para a criação de Comitês de Bacia Hidrográfica; VIII - implementar, em articulação com os Comitês de Bacia Hidrográfica, a cobrança pelo uso de recursos hídricos de domínio da União; IX - arrecadar, distribuir e aplicar receitas auferidas por intermédio da cobrança pelo uso de recursos hídricos de domínio da União, na forma do disposto no art. 22 da Lei $n^{\circ}$ 9.433, de 1997; X - planejar e promover ações destinadas a prevenir ou minimizar os efeitos de secas e inundações, no âmbito do Sistema Nacional de Gerenciamento de Recursos Hídricos, em articulação com o órgão central do Sistema Nacional de Defesa Civil, em apoio aos Estados e Municípios; XI promover a elaboração de estudos para subsidiar a aplicação de recursos financeiros da União em obras e serviços de regularização de cursos de água, de alocação e distribuição de água, e de controle da poluição hídrica, em consonância com o estabelecido nos planos de recursos hídricos; XII - definir e fiscalizar as condições de operação de reservatórios por agentes públicos e privados, visando a garantir o uso múltiplo dos recursos hídricos, conforme estabelecido nos planos de recursos hídricos das respectivas bacias hidrográficas; XIII - promover a coordenação das atividades desenvolvidas no âmbito da rede hidrometeorológica nacional, em articulação com órgãos e entidades públicas ou privadas que a integram, ou que dela sejam usuárias; XIV organizar, implantar e gerir o Sistema Nacional de Informações sobre Recursos Hídricos; XV - estimular a pesquisa e a capacitação de recursos humanos para a gestão de recursos hídricos; XVI - prestar apoio aos Estados na criação de órgãos gestores de recursos hídricos; XVII - propor ao Conselho Nacional de Recursos Hídricos o estabelecimento de incentivos, inclusive financeiros, à conservação qualitativa e quantitativa de recursos hídricos. XVIII - participar da elaboração do Plano Nacional de Recursos Hídricos e supervisionar a sua implementação; XIX - regular e fiscalizar, quando envolverem corpos d'água de domínio da União, a prestação dos serviços públicos de 
irrigação, se em regime de concessão, e adução de água bruta, cabendo-lhe, inclusive, a disciplina, em caráter normativo, da prestação desses serviços, bem como a fixação de padrões de eficiência e o estabelecimento de tarifa, quando cabíveis, e a gestão e auditagem de todos os aspectos dos respectivos contratos de concessão, quando existentes; XX - organizar, implantar e gerir o Sistema Nacional de Informações sobre Segurança de Barragens (SNISB); XXI - promover a articulação entre os órgãos fiscalizadores de barragens; XXII - coordenar a elaboração do Relatório de Segurança de Barragens e encaminhá-lo, anualmente, ao Conselho Nacional de Recursos Hídricos (CNRH), de forma consolidada.

O SINGREH é uma entidade singular, isso dar-se em virtude da bacia hidrográfica ser a base territorial para implantação da $\mathrm{PNRH}$, tendo como aliado os comitês das bacias hidrográficas, os quais possuem as seguintes competências, conforme disposto na Lei no 9.433/97, art. 38:

I - promover o debate das questões relacionadas a recursos hídricos e articular a atuação das entidades intervenientes; II - arbitrar, em /primeira instância administrativa, os conflitos relacionados aos recursos hídricos; III - aprovar o Plano de Recursos Hídricos da bacia; IV - acompanhar a execução do Plano de Recursos Hídricos da bacia e sugerir as providências necessárias ao cumprimento de suas metas; $\mathrm{V}$ - propor ao Conselho Nacional e aos Conselhos Estaduais de Recursos Hídricos as acumulações, derivações, captações e lançamentos de pouca expressão, para efeito de isenção da obrigatoriedade de outorga de direitos de uso de recursos hídricos, de acordo com os domínios destes; $\mathrm{VI}$ - estabelecer os mecanismos de cobrança pelo uso de recursos hídricos e sugerir os valores a serem cobrados [...]; IX - estabelecer critérios e promover o rateio de custo das obras de uso múltiplo, de interesse comum ou coletivo.

Em decorrência da existência desses comitês das bacias hidrográficas surge a necessidade de outro órgão de caráter executivo que são as agências de água, vinculadas aos comitês de bacias hidrográficas, tendo as seguintes atribuições, conforme determina o art. 44, da Lei no 9.433/97:

I - manter balanço atualizado da disponibilidade de recursos hídricos em sua área de atuação; II - manter o cadastro de usuários de recursos hídricos; III - efetuar, mediante delegação do outorgante, a cobrança pelo uso de recursos hídricos; IV - analisar e emitir pareceres sobre os projetos e obras a serem financiados com recursos gerados pela cobrança pelo uso de Recursos Hídricos e encaminhá-los à instituição financeira responsável pela administração desses recursos; V - acompanhar a administração financeira dos recursos arrecadados com a cobrança pelo uso de recursos hídricos em sua área de atuação; VI - gerir o Sistema de Informações sobre Recursos Hídricos em sua área de atuação; VII - celebrar convênios e contratar financiamentos e serviços para a execução de suas competências; VIII - elaborar a sua proposta orçamentária e submetê-la à apreciação do respectivo ou respectivos Comitês de Bacia Hidrográfica; IX - promover os estudos necessários para a gestão dos recursos hídricos em sua área de atuação; $X$ - elaborar o Plano de Recursos Hídricos para apreciação do respectivo Comitê de Bacia Hidrográfica; XI - propor ao respectivo ou respectivos Comitês de Bacia Hidrográfica: a) o enquadramento dos corpos de água nas classes de uso, para

Planeta Amazônia: Revista Internacional de Direito Ambiental e Políticas Públicas 
encaminhamento ao respectivo Conselho Nacional ou Conselhos Estaduais de Recursos Hídricos, de acordo com o domínio destes; b) os valores a serem cobrados pelo uso de recursos hídricos; c) o plano de aplicação dos recursos arrecadados com a cobrança pelo uso de recursos hídricos; d) o rateio de custo das obras de uso múltiplo, de interesse comum ou coletivo.

Além dessas atribuições legais específicas as agências de água, a ANA poderá delegalas a execução de atividades de sua competência, tendo em vista a compatibilidade dessas atividades com a previsão do art. 44 da PNRH. Outra característica importante é que assim como o SISNAMA, o SINGREH possui órgãos seccionais e locais responsáveis pelas administrações e fiscalizações em âmbito estadual e municipal.

Ou seja, além de Conselhos Estaduais de Recursos Hídricos, compõem o SINGREH todos os órgãos estaduais, do Distrito Federal e municipais relacionados com a gestão de recursos hídricos, tendo suas competências delimitadas pela CRFB de 1988. Pode-se citar o exemplo, o Estado do Rio Grande do Norte que por intermédio da Lei Estadual de no 8.086, de 15 de abril de 2002 criou o Instituto de Gestão das Águas do Estado do Rio Grande do Norte (GARN), autarquia vinculada à Secretaria de Estado de Recursos Hídricos (SERHID). Já no município de Natal as atribuições de proteção aos recursos hídricos ficaram sob os auspícios da Secretaria Municipal de Meio Ambiente e Urbanismo (SEMURB) (NATAL, Lei no 4.100/1992, art. 7ㅇ, XII).

\section{CONSIDERAÇÕES FINAIS}

A água por ser um elemento necessário a sobrevivência dos seres vivos, bem como, a crescente escassez de água doce potável para consumo e sua grande importância para a produção de energia elétrica fez com que hodiernamente se busque a regulação do seu uso e sua preservação para as gerações futuras, tendo por fito o desenvolvimento sustentável. Na busca de preservar e usar de forma sustentável tal bem econômico e em decorrência do novo modelo de administração pública criou-se o SINGREH, previsto na Lei $n^{\circ} 9.433 / 97$ que institui a PNRH.

Esse modelo de gerenciamento de recursos hídricos é composto pelo: CNRH, ANA, Conselhos de Recursos Hídricos dos Estados e do Distrito Federa, Comitês de Bacia Hidrográfica, os órgãos dos poderes públicos federal, estaduais, do Distrito Federal e municipais cujas competências se relacionem com a gestão de recursos hídricos e Agências de Água.

Outra constatação é que por meio da Lei $n^{\circ} 9.984 / 00$, sob a figura de uma autarquia em regime especial criou-se a ANA com o fim de implementação da PNRH e de coordenação do SINGREH. Essa formatação de entidades administrativas e suas respectivas atribuições tem o fito de um gerenciamento racional e sustentável do uso da água, bem como reconhecimento por norma constitucional de que esse elemento natural é um bem público, é o prelúdio para que se possa alcançar um Brasil no qual todos tenham acesso a esse recurso natural, efetivando, assim, os direitos a vida, liberdade, desenvolvimento corolário do axioma da dignidade da pessoa humana. 


\section{REFERÊNCIAS}

ANTUNES, Paulo de Bessa. Direito Ambiental. 10 ed. Rio de Janeiro: Editora Lúmen Juris, 2007.

BORSOI, Zilda Maria Ferrão; TORRES, Solange Domingo Alencar. A política de recursos hídricos no Brasil. Revista do BDNES. Rio de janeiro, Dez. 1997. Disponível em: <http://www.bndes.gov.br/SiteBNDES/export/sites/default/bndes_pt/Galerias/Arquivos/con hecimento/revista/rev806.pdf >. Acesso em: 11 de dezembro de 2013.

BRASIL. Agência Nacional de Águas. A água no Brasil e no mundo. Brasília, 2006. Disponível em: <http://www.ana.gov.br/GestaoRecHidricos/InfoHidrologicas/mapasSIH/1-AAguaNoBra silENoMundo.pdf>. Acesso em: 20 de dezembro de 2013.

. Constituição (1988). Constituição da República Federativa do Brasil: promulgada em 05 de outubro de 1988.

BRASIL. Lei no 6.938, de 31 de agosto de 1981. Dispõe sobre a Política Nacional do Meio Ambiente, seus fins e mecanismos de formulação e aplicação, e dá outras providências. Publicado no Diário Oficial da União, em 02.09.1981.

. Lei no 9.433, 8 de janeiro de 1997. Institui a Política Nacional de Recursos Hídricos,

cria o Sistema Nacional de Gerenciamento de Recursos Hídricos, regulamenta o inciso XIX do art. 21 da Constituição Federal, e altera o art. 1ㅇ da Lei no 8.001, de 13 de março de 1990, que modificou a Lei no 7.990, de 28 de dezembro de 1989. Publicada no Diário Oficial da União em 09.01.1997

Portaria/MS no 518, de 25 de março de 2004. Estabelece os procedimentos e responsabilidades relativos ao controle e vigilância da qualidade da água para consumo humano e seu padrão de potabilidade, e dá outras providências. Publicada no Diário Oficial da União em 26.03.2004 (Revogada).

BRUNONI, Nivaldo. A tutela das águas no município. In: FREITAS. Vladimir Passos de (coord.). Águas: aspectos jurídicos e ambientais. 7o ed. Curitiba: Juruá, 2008.

CARVALHO, Rodrigo Speziali de. Água, um bem que precisa ser cuidado. Brasília: ANA, 2004. Disponível em: <http://www.cnrh.gov.br/index.php?option=com_docman\&task=cat_view\&gi $\mathrm{d}=133$ \&Itemid=130>. Acesso em: 20 de dezembro de 2013.

CAUBET, Christian Guy. A água, a lei, a política... e o meio ambiente? Curitiba: Juruá, 2006. CUSTÓDIO, Helita Barreira. Princípios constitucionais da proteção das águas. IN: KISHI, Sandra Akemi Shimada; SILVA, Solange Teles da; SOARES, Inês Virgínia Prado (orgs.). Desafios do direito ambiental no século XXI - estudos em homenagem a Paulo Affonso Leme Machado. São Paulo: Malheiros Editora, 2005.

Declaração de Estocolmo sobre o Meio Ambiente Humano (1972). Disponível em: <https:// www.apambiente.pt/_zdata/Politicas/DesenvolvimentoSustentavel/1972_Declaracao_Estoco Imo.pdf>. Acesso em 30 mar. 2013.

FREITAS, Vladimir Passos de. Águas - considerações gerais. FREITAS, Vladimir Passos de (coord.). Águas: aspectos jurídicos e ambientais. 70 ed. Curitiba: Juruá, 2008.

GRAF, Ana Cláudia Bento. A tutela dos Estados Sobre as Águas. In: FREITAS. Vladimir Passos 
de (coord.). Águas: aspectos jurídicos e ambientais. 70 ed. Curitiba: Juruá, 2008.

LEUZINGER, Márcia. Recursos hídricos. IN: RIOS, Aurélio Virgílio Veiga; IRIGARY, Carlos Teodoro Hugueney (orgs.). $\mathrm{O}$ direito e o desenvolvimento sustentável. São Paulo: Editora Petrópolis, 2005.

MACHADO, Paulo Affonso Leme. Recursos Hídricos. São Paulo: Malheiros, 2002.

MILARÉ, Édis. Direito do ambiente. 5 ed. São Paulo: RT, 2007.

POMPEU, Cid Tomanik. Direito de águas no Brasil.São Paulo, RT, 2007.

SETTI, Arnaldo A. et all; LIMA, Jorge Enoch Furquim Wernck; CHAVES, Adriana Goretti de Miranda; PEREIRA, Isabella de Castro. Introdução ao gerenciamento de recursos hídricos. 2. Ed. Brasília: ANEEL/ANA, 2001. Disponível em: <http://www.ana.gov.br/AcoesAdministrativas/ CDOC/CatalogoPublicacoes_2002.asp>. Acesso em: 20 de dezembro de 2013.

SILVA, José Afonso da. Direito ambiental constitucional. 6 ed. São Paulo: Malheiros, 2007.

SILVEIRA NETO, Otacílio dos Santos. A propriedade da água no Brasil. In: XAVIER, Yanko Marcius de Alencar; IRUJO, Antonio Embid; SILVEIRA NETO, Otacílio dos Santos (orgs.). 0 direito de águas no Brasil e na Espanha: um estudo comparado. Fortaleza: Konrad-Adenauer-sifung, 2008.

SIRVINSKAS, Luís Paulo. Manual de direito ambiental. $2^{\circ}$ ed. São Paulo: Saraiva, 2003, p. 34 e; RODRIGUES, Marcelo Abelha. Elementos de direito ambiental - parte geral. $2^{\circ}$ ed. São Paulo: RT, 2005.

SUPREMO TRIBUNAL FEDERAL (STF), PLENO, ADI-MC 3540/DF, rel. Min. Celso de Mello, DJU 03.02.2006.

VIEGAS, Eduardo Coral. Visão jurídica da água. Porto Alegre: Livraria do Advogado, 2005.

WPI, Water Poverty Index <http://www.ecoviagem.com.br/fique-por-dentro/noticias/ambi ente/nossa-agua/wpi-apresentou-um-novo-indice-mostrando-as-dez-mais-ricas-nacoes-emagua-2053.asp>. Acessado em: 14 de dezembro de 2013.

XAVIER, Yanko Marcius de Alencar. Gestão legal dos recursos hídricos do Nordeste do Brasil. XAVIER, Yanko Marcius de Alencar; BEZERRA, Nizomar Falcão (orgs.). Gestão Legal dos Recursos Hídricos do Nordeste Brasileiro. Fortaleza: Konrad-Adenauer-sifung, 2004.

Artigo recebido em 20 de abril de 2017.

Aprovado em 24 de abril de 2018. 